\title{
A COUNTEREXAMPLE TO THE ARTICLE “ON THE FIXED POINTS OF AFFINE NONEXPANSIVE MAPPINGS”
}

\author{
SHAHRAM SAEIDI \\ Received 6 October 2006; Accepted 30 October 2006
}

We give a counterexample to the article "On the fixed points of affine nonexpansive mappings" (2001).

Copyright (c) 2006 Hindawi Publishing Corporation. All rights reserved.

Let $K$ be a nonempty, closed convex subset of a real Banach space $E$. A mapping $T: K \rightarrow K$ is said to be nonexpansive if $\|T x-T y\| \leq\|x-y\|$ for all $x, y \in K$. T is said to be affine if for each $x, y \in K$ and $0<\lambda<1, T(\lambda x+(1-\lambda) y)=\lambda T x+(1-\lambda) T y$.

In the main theorem of the above-referenced paper [2, Theorem 2.4], the author proves that when $K$ is a nonempty, closed convex and bounded subset of $E$ and $T: K \rightarrow K$ is a nonexpansive and affine mapping, then it has a fixed point in $K$.

Here, we give an example to show that the mentioned theorem above is not correct.

\section{Counterexample}

We consider $c_{0}$, the real Banach space of all sequences $\left(x_{1}, x_{2}, \ldots, x_{n}, \ldots\right)$ such that $\lim _{n \rightarrow \infty} x_{n}=0$, equipped by the maximum norm (i.e., $\left.\left\|\left(x_{1}, x_{2}, \ldots, x_{n}, \ldots\right)\right\|:=\max _{n}\left|x_{n}\right|\right)$. Define $T: B_{1} \rightarrow B_{1}$ by $T\left(x_{1}, x_{2}, \ldots\right):=\left(1, x_{1}, x_{2}, \ldots\right)$ for each $x=\left(x_{1}, x_{2}, \ldots\right)$ in $B_{1}$, where $B_{1}$ is the closed unit ball in $c_{0}$. It is easy to show that $\|T x-T y\|=\|x-y\|$, for every $x, y$ in $B_{1}$ and also that $T$ is affine. Therefore, the conditions of the main theorem of [2] hold. However, $T$ does not have a fixed point.

It is worth mentioning that if we impose weak compactness on $K$, then the theorem will be true. For details and some other related results, it is convenient to see $[1,3]$ and most importantly [4].

\section{References}

[1] T. D. Benavides, M. A. Japón Pineda, and S. Prus, Weak compactness and fixed point property for affine mappings, Journal of Functional Analysis 209 (2004), no. 1, 1-15.

[2] H. Duru, On the fixed points of affine nonexpansive mappings, International Journal of Mathematics and Mathematical Sciences 28 (2001), no. 11, 685-688. 


\section{A counterexample}

[3] M. Edelstein and K.-K. Tan, Fixed point theorems for affine operators on vector spaces, Journal of Mathematical Analysis and Applications 181 (1994), no. 1, 181-187.

[4] L. Gajek, J. Jachymski, and D. Zagrodny, Fixed point and approximate fixed point theorems for non-affine maps, Journal of Applied Analysis 1 (1995), no. 2, 205-211.

Shahram Saeidi: Department of Mathematics, Azad University, Sanandaj Branch, Kurdistan, Iran; Department of Mathematics, Kurdistan University, Iran

E-mail address: shahram_saeidi@yahoo.com 


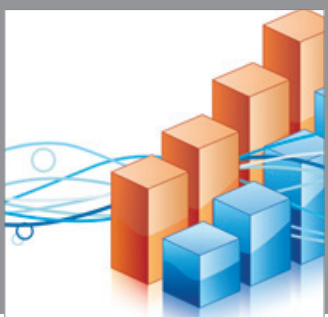

Advances in

Operations Research

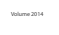

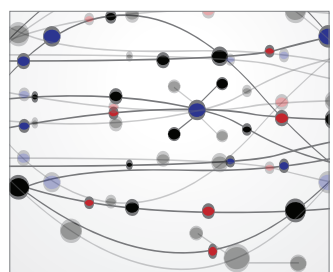

\section{The Scientific} World Journal
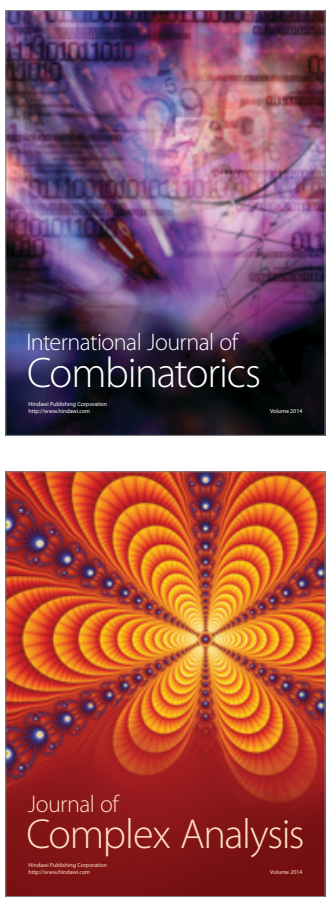

International Journal of

Mathematics and

Mathematical

Sciences
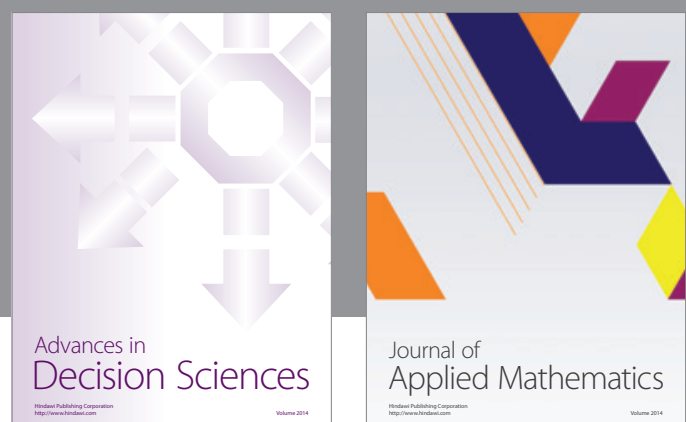

Journal of

Applied Mathematics
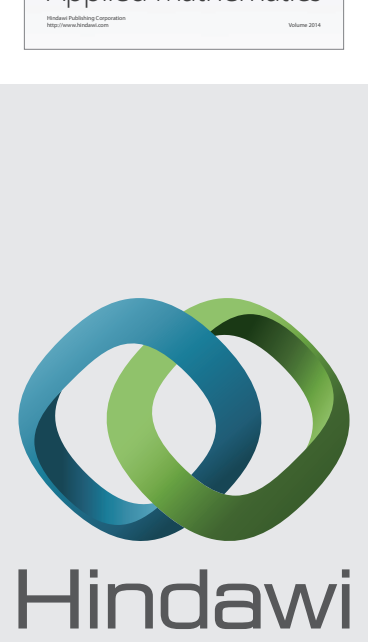

Submit your manuscripts at http://www.hindawi.com
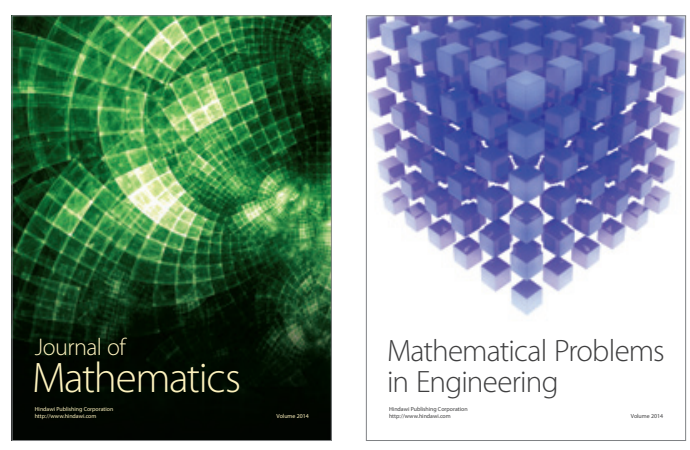

Mathematical Problems in Engineering
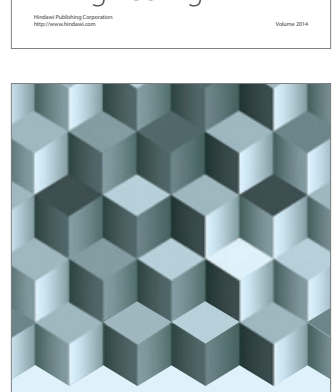

Journal of

Function Spaces
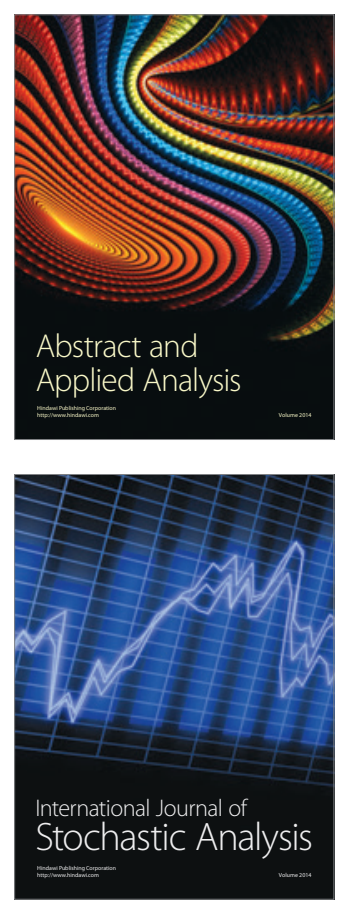

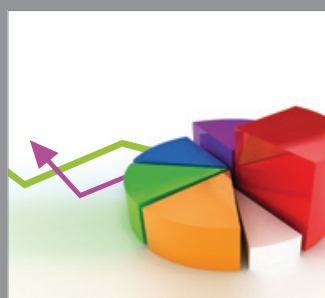

ournal of

Probability and Statistics

Promensencen
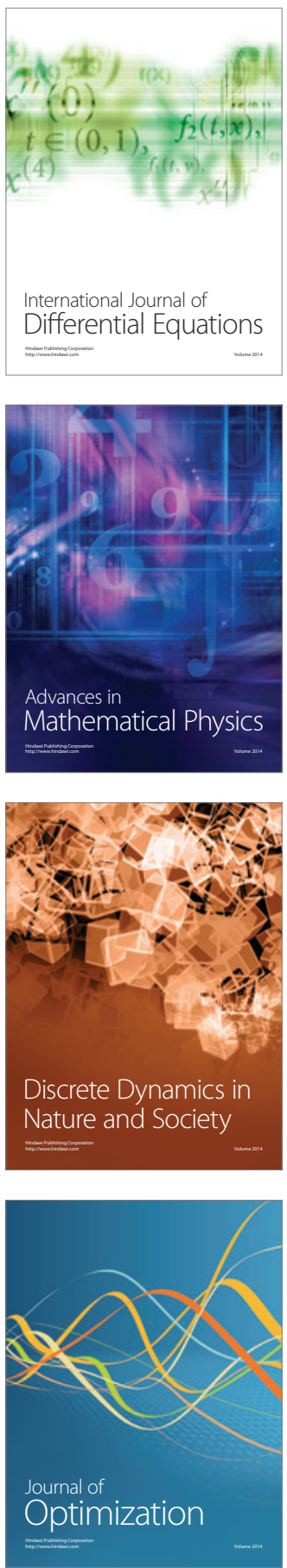